\title{
Can gallbladder wall thickness by gross examination predicts its carcinoma before histopathological study?
}

\author{
Navyashree N. ${ }^{1}$, Giriyan S.S. ${ }^{2}$ \\ ${ }^{1}$ Dr. Navyashree N. Resident doctor, ${ }^{2}$ Dr. Sujata S. Giriyan, Professor and Head of the Department; both authors are affiliated \\ with Department of Pathology, Karnataka Institute of Medical Sciences, Hubballi, Karnataka, India.
}

Corresponding Author: Dr. Navyashree N., Department of Pathology, Karnataka Institute of Medical Sciences, Hubballi, Karnataka. Email: nav.sourabha@gmail.com

\begin{abstract}
Background: The gallbladder lesions are often underappreciated. Though gallbladder carcinomas are less in incidence, it is important to examine all gallbladders on removal so that carcinomas are not missed. In this regard, this study is about predicting the risk of carcinoma gallbladder on gross examination, so that no carcinoma cases are missed and also unnecessary histopathological examination of non-neoplastic conditions which forms the major bulk of gallbladder pathology can be avoided. Objectives: 1) To study gross and microscopic features of gallbladder in cholecystectomy specimens. 2) To study association of gross features and carcinoma of gallbladder. Methods: A 4 years study was conducted on 316 specimens of cholecystectomy in KIMS, Hubballi from June 2014 to May 2018. Gallbladder specimens were processed by standard procedures and histopathological patterns were studied. Results: The present study included patients from 7 to 87 years of age with Male: Female ratio $1: 1.8$ and majority were in $5^{\text {th }}$ and $7^{\text {th }}$ decade. Chronic cholecystitis $(78.6 \%)$ was most common gallbladder lesion. Incidence of gallbladder carcinoma was $1.89 \%$ and majority were in $7^{\text {th }}$ decade. Statistically significant association was found between carcinoma and increased thickness of gallbladder wall.
\end{abstract}

Keywords: Carcinoma, Cholecystitis, Gallbladder, Gall bladder wall thickness.

\section{Introduction}

Gallstones are the commonest biliary pathology and more than $95 \%$ of biliary tract disease is attributable to cholelithiasis (gallstones). The current changes in lifestyles of individuals pertaining to indulgence in unhealthy fat-rich food, lack of exercise, obesity, sedentary lifestyles and various other factors have once again focused our attention to gall stones and diseases of the gall bladder [1].

Obstruction caused due to gallstones leads to development of chronic cholecystitis which, in turn predisposes to carcinoma of gallbladder. Gallstones present for a longer period predispose for carcinoma of gall bladder. Cholelithiasis is found in approximately $85 \%$ of people with gallbladder cancer. The association between cholelithiasis and gallbladder cancer ranges from 2.3 to 34.4 in case control studies [1].

Gall bladder carcinoma ranks $5^{\text {th }}$ in the gastrointestinal malignant tumours [2] and due to non-specific clinical presentation, it is rarely diagnosed at an early stage. Preoperative imaging techniques fail to identify the

Manuscript received: $10^{\text {th }}$ November 2019

Reviewed: $20^{\text {th }}$ November 2019

Author Corrected: $26^{\text {th }}$ November 2019

Accepted for Publication: $30^{\text {th }}$ November 2019 premalignant and malignant lesions. Incidental gallbladder cancer is found in up to $1 \%$ of cholecystectomy specimens for gallstone disease, which recommend routine histopathology of all cholecystectomy specimens [3]. But if it is possible to predict the risk of carcinoma by gross examination of specimen, it will guide in taking adequate samples for further microscopic examination and also will reduce the burden on histopathologists.

\section{Objectives}

1. To study gross and microscopic features of gallbladder in cholecystectomy specimens.

2. To study association of gross features and carcinoma of gallbladder.

Carcinoma of the gallbladder: Carcinoma of the gallbladder is the most common malignancy of the extrahepatic biliary tract [4] Female to male ratio is 1.77 , seen mainly in $6^{\text {th }}-7^{\text {th }}$ decade of life [5].

Incidence rates are more in American Indians, Hispanic Americans and people of Mexico, Central and South America, eastern Europe and in parts of Asia [6].

Pathology Update: Tropical Journal of Pathology \& Microbiology Available online at: www.medresearch.in 1039|P a g e 
Grossly, gallbladder carcinoma may present as a diffusely growing $(70 \%)$ or polypoidal $(30 \%)$ mass. Usually it will be infiltrating grey-white mass, may be associated with diffuse thickening and induration of the entire gallbladder wall. Carcinoma arising in association with intracystic papillary neoplasms may be sessile or polypoid. Mucinous and signet ring cell carcinomas have a mucoid or gelatinous cut surface [7].

Microscopically, most gallbladder cancers are adenocarcinomas showing varying degrees of differentiation. Most tumours have a morphologic appearance that is common to adenocarcinomas of the pancreaticobiliary region: well-formed glands with wide lumina lined by one or a few rows of highly atypical cuboidal cells, surrounded by a cellular stroma often arranged concentrically. It is characteristic for these glands to be well differentiated at an architectural level but poorly differentiated at cytological level [8].

\section{Methodology}

Setting: The present study was conducted in the Department of Pathology, Karnataka Institute of Medical Sciences, Hubballi.

Duration: Four years extending from June 2014 to May 2018

Type of study: Descriptive study
Sampling methods: All the cholecystectomy specimens were studied which satisfied inclusion and exclusion criteria

Sample size calculation: 316 cholecystectomy specimens

Inclusion criteria: All cases of cholecystectomy were included in the study.

Exclusion criteria: Autolysed and gangrenous specimens were excluded from this study.

Data collection procedure: The gall bladder specimens were collected in $10 \%$ formalin following scrutinizing the patient details and identity. The gallbladder specimens were cut and fixed in fresh formalin for 24 hours. Detailed gross examinations were carried out and descriptions of the specimens were noted. Tissue bits were taken from representative areas of the fundus, body and neck of the gall bladder and additional tissue bits were taken from abnormal appearing areas. This was followed by processing with routine histopathological examination.

Data analysis: Statistical analysis was done using SPSS software. Chi square test was used wherever necessary.

Ethical consideration \& permission: Patient's consent and ethical clearance was obtained before starting the study. Any scoring system: No

Surgical procedure: Included both open and laparoscopic cholecystectomies

\section{Results}

Spectrum of overall lesions of gallbladder in the present study. Out of total 316 cases, majority of the study population were having chronic cholecystitis (248 cases, 78.6\%), followed by acute cholecystitis ( 27 cases, 8.6\%), acute on chronic cholecystitis (26 cases, 8.2\%), adenocarcinoma of gallbladder (6 cases, 1.9\%), xanthogranulomatous cholecystitis, tubular adenoma, eosinophilic cholecystitis (each group had 2 cases each, $0.6 \%$ ) and least reported were cholesterol polyp, cholecystitis glandularis proliferans and empyema of gallbladder ( 1 case in each group, $0.3 \%$ ), as shown in Table 1.

Table-1: Distribution of various histopathological lesions of gallbladder in the present study.

\begin{tabular}{|l|c|c|}
\hline Histopathological lesions & No. of patients & Percentage \\
\hline Acute cholecystitis & 27 & 8.6 \\
\hline Acute on chronic cholecystitis & 26 & 8.2 \\
\hline Adenocarcinoma of gallbladder & 6 & 7.9 \\
\hline Chronic cholecystitis & 248 & 0.3 \\
\hline Cholecystitis glandularis proliferans & 1 & 0.3 \\
\hline Cholesterol polyp & 1 & 0.3 \\
\hline Empyema of gallbladder & 1 & 0.6 \\
\hline Eosinophilic cholecystitis & 2 & 0.6 \\
\hline Tubular adenoma & 2 & 0.6 \\
\hline Xanthogranulomatous cholecystitis & 2 & $\mathbf{1 0 0}$ \\
\hline Total & $\mathbf{3 1 6}$ & \\
\hline
\end{tabular}

Out of 316 cholecystectomy specimens, there were 6 cases of adenocarcinoma gallbladder. The frequency of gallbladder adenocarcinoma was $1.89 \%$ (Figure1). 


\section{Adenocarcinoma of Gallbladder}

- Total number of adenocarcinoma cases
- Total number of cholecystectomy specimens $1.89 \%$

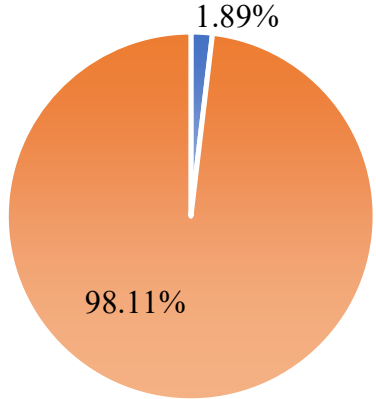

Fig-1: Pie chart showing percentage of gallbladder adenocarcinoma cases in the present study.

Out of 6 adenocarcinoma gallbladder cases, 4 cases were associated with calculi $(66.7 \%)$, which constituted majority of cases and in 2 cases $(33.3 \%)$ calculus was not found, as shown in Table 2.

Table-2: Association of adenocarcinoma gallbladder with gallstones in the present study

\begin{tabular}{|c|c|c|}
\hline Adenocarcinoma of gallbladder & Number of patients & Percentage (\%) \\
\hline Associated with calculi & 4 & $66.7 \%$ \\
\hline Not associated with calculi & 2 & $33.3 \%$ \\
\hline Total & $\mathbf{6}$ & $\mathbf{1 0 0 \%}$ \\
\hline
\end{tabular}

In the present study for the data obtained, the Chi-square statistic was 0.2657 . The p-value was 0.606233 . This result was not significant at $\mathrm{p}<0.05$. Therefore, according to the present study there was no statistical significance between the malignancy and gallbladder calculi. Hence the association of presence of gallstones with carcinoma gallbladder could not be considered (Table 3).

Table-3: Statistical association of gallstones with gallbladder carcinoma in the present study

\begin{tabular}{|c|c|c|c|c|c|}
\hline & & \multicolumn{2}{|c|}{ Adenocarcinoma gallbladder } & Total & Chi square test \\
\hline \multirow{2}{*}{ Calculi } & & Present & Absent & & \multirow{2}{*}{$\begin{array}{c}\chi^{2}=0.26 \\
\mathrm{P}=0.606233 \\
\end{array}$} \\
\cline { 2 - 5 } & Present & 4 & 174 & $\mathbf{1 7 8}$ & $\mathbf{1 3 8}$ \\
(not significant) \\
\cline { 1 - 4 } Total & & 2 & 136 & $\mathbf{3 1 6}$ & \\
\hline
\end{tabular}

Gross features: External surface of all 6 cases of adenocarcinoma gallbladder were congested, enlarged in 2 cases and perforation was seen in one case. On cut section lumen was filled with bile in 2 cases, sludge in 3 cases and grey white, firm, granular mass was seen in all cases of adenocarcinoma gallbladder. Mucosa was congested in 4 cases, granular in 2 cases and diffuse thickening of gallbladder wall was seen in 5 cases. (Figure 2)

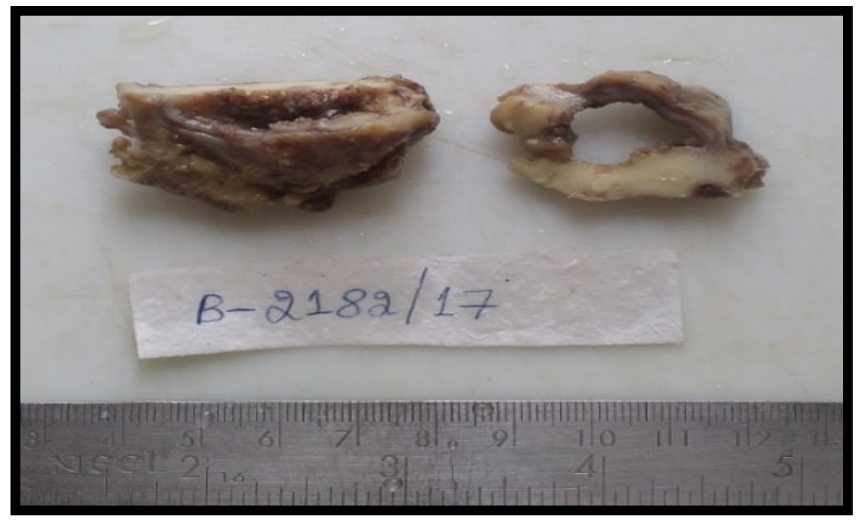

Fig-2: Gross photograph of adenocarcinoma of the gallbladder. Cut surface showing grey-white, granular, firm, diffuse thickening of the gallbladder wall at the fundus measuring $3 * 3 \mathrm{~cm}$. 
Gross features of mass: Out of 6 cases of adenocarcinoma gallbladder, mass was seen in fundus in 4 cases (66.66\%), in body in one case (16.67\%) and involving both fundus and body in one case (16.67\%); fundus was the most common site involved. All of them were showing mass which was grey white in colour, granular and firm in consistency. Five cases had grey white irregular growth (5 cases, $83.34 \%$ ) and only one case $(16.66 \%)$ had polypoidal growth. Out of 6 cases, one case showed focal mucoid areas (17\%), as shown in Table 4, Figure 3 A and B.

Table-4: Gross features of mass in adenocarcinoma gallbladder in the present study

\begin{tabular}{|c|c|c|}
\hline Nature of the mass in the gallbladder & Number of carcinoma gallbladder & Percentage \\
\hline Grey white irregular growth & 5 & $83.34 \%$ \\
\hline Polypoidal growth & 1 & $16.66 \%$ \\
\hline Total & $\mathbf{6}$ & $\mathbf{1 0 0 \%}$ \\
\hline
\end{tabular}
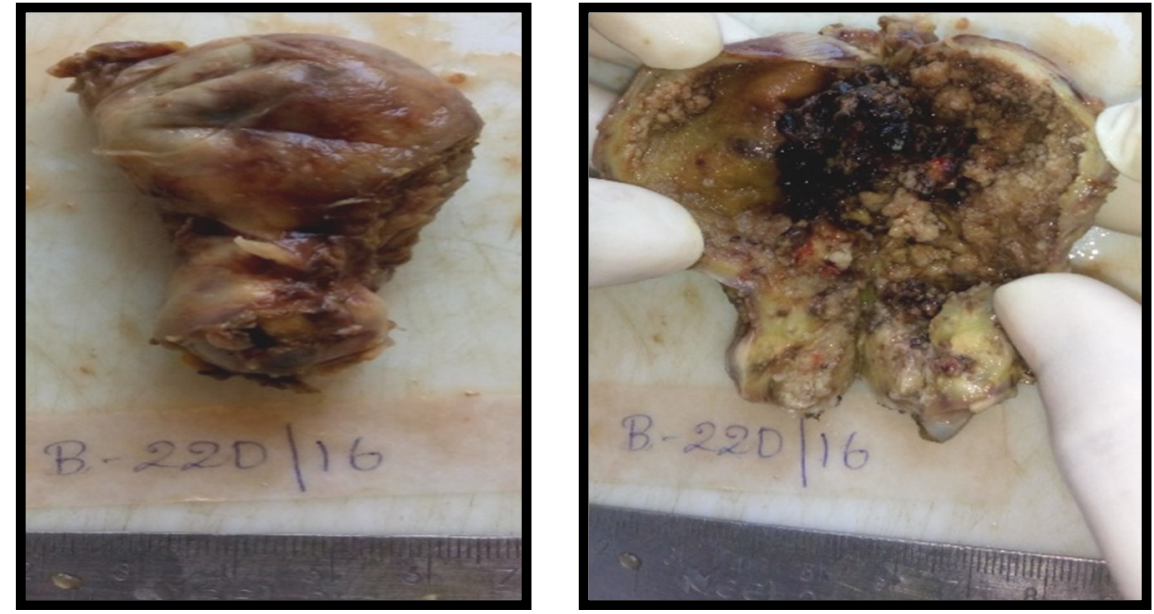

Figure 3: A. Gross photograph of adenocarcinoma of the gallbladder showing congested external surface. B. Cut surface showing grey-white to grey-brown, granular mucosa showing tiny papillary projections involving neck, body and fundus of the gallbladder measuring $4 * 3.5 \mathrm{~cm}$. There also found firm, diffuse thickening of the gallbladder wall.

In the present study for the data obtained, the Chi-square statistic was 5.625. The p-value was 0.017706 . This result was significant at $\mathrm{p}<0.05$. Therefore, according to the present study there was statistically significance between the malignancy and thickness of gallbladder. Hence the association of presence of thickened gallbladder with carcinoma gallbladder could be considered. And also, gross examination of thickened gallbladder should alert both the surgeon and the pathologists to rule out carcinoma gallbladder (Table 5).

Table-5: Statistical association of thickness of gallbladder with gallbladder carcinoma in the present study.

\begin{tabular}{|c|c|c|c|c|c|}
\hline & & \multicolumn{2}{|c|}{ Adenocarcinoma gallbladder } & Total & $\begin{array}{c}\text { Chi square } \\
\text { test }\end{array}$ \\
\hline & & Present & Absent & & $\chi^{2}=5.625$ \\
\multirow{2}{*}{$\begin{array}{c}\text { Gall bladder wall } \\
\text { thickness (>3mm) }\end{array}$} & Present & 5 & 112 & 117 & $\begin{array}{c}\mathrm{P}=0.017706 \\
\text { (Significant) }\end{array}$ \\
\cline { 2 - 6 } & Absent & 1 & 198 & 199 & \\
\hline Total & & $\mathbf{6}$ & $\mathbf{3 1 0}$ & $\mathbf{3 1 6}$ & \\
\hline
\end{tabular}

Microscopy: Out of 6 cases of gallbladder carcinoma, 4 (66.67\%) cases were found to be well differentiated adenocarcinoma, 1 case $(16.67 \%)$ was mucin secreting adenocarcinoma and another one $(16.66 \%)$ was poorly differentiated adenocarcinoma. In 4 cases tumour cells was invading muscularis propria but no extension into serosa and in 2 cases tumour cells were seen infiltrating serosa (Figure 4). 

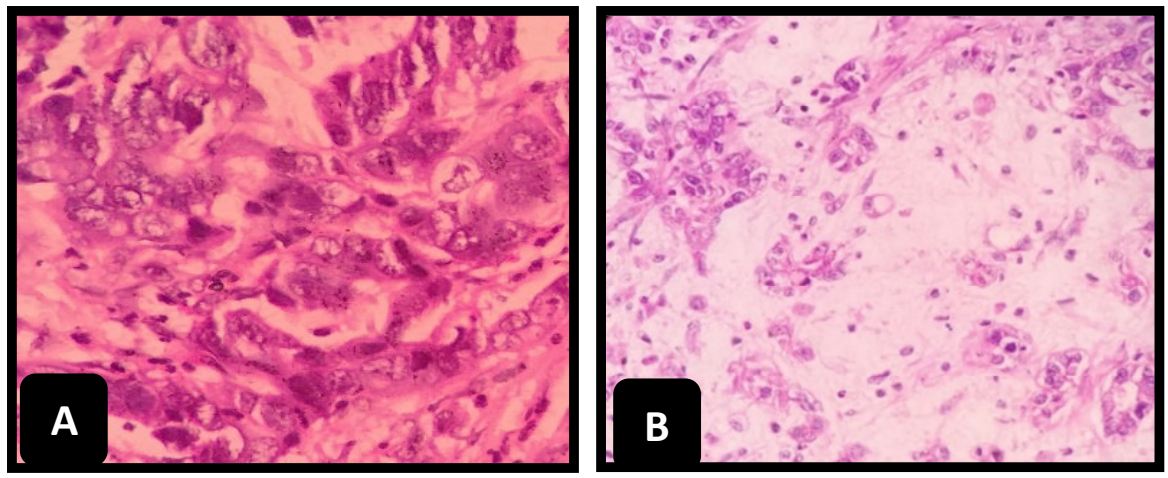

Fig-4: A: Photomicrograph of adenocarcinoma of the gallbladder showing dysplastic mucosa, complex branching of the glandular structures and infiltration of tumour cells into muscularis propria. These tumour cells are highly pleomorphic, hyperchromatic, irregular nucleus and moderate amount of cytoplasm (A: H\&E stain-40x).B: Photomicrograph of mucin secreting adenocarcinoma of the gallbladder showing tumour cells arranged in glandular pattern with nuclear pleomorphism, coarse nuclear chromatin, prominent nucleoli with moderate amount of eosinophilic cytoplasm, some showing vacuolation. Tumour cells seen floating in mucinous pool in singles and in groups. (H\&E stain-40x).

\section{Discussion}

Carcinoma of gallbladder: Gallbladder carcinoma is the fifth most common malignancy of the gastrointestinal tract, which is found incidentally in $1 \%$ to $3 \%$ of cholecystectomy specimens [9]. Due to lack of early or specific symptoms, it is often detected at later stage. Though cholecystitis, adenomyomatosis, congestive right heart failure and hepatitis etc, causes gallbladder wall thickening; carcinoma gallbladder causing wall thickness should not be neglected. And it has to be differentiated from benign lesions by histopathological examination. Grossly, gallbladder carcinoma may present as a diffusely growing (70\%) or polypoidal (30\%) mass. Usually it will be infiltrating greywhite mass, associated with focal or diffuse thickening and induration of the entire gallbladder wall [7].

Comparison of incidence of gallbladder carcinoma in the present study with other studies: Incidence of carcinoma gallbladder found in the present study was $1.89 \%$ ( 6 cases), which correlated very well to the incidence found in the study conducted by Murmu S et al [10] (2 cases, $1.88 \%$ ), Kumar $\mathrm{H}$ et al [11] (North Indian data- 8 cases, $2 \%$, South Indian data- 5 cases, $1.25 \%$ ) and the study by Kumari G et al [12] (7 cases, 1.27\%). A lower incidence was observed in studies done by Beena D et al [13] (1 case, $0.5 \%$ ), Mondal B et al [14] (5 cases, 0.6\%), Sharma I et al [15] (3 cases, 0.86\%) and H Mohan et al [16] (12 cases, $1.09 \%)$.

Comparison of characteristics of growth in gallbladder carcinoma of the present study with other studies: In the present study, 5 cases of gallbladder carcinomas were having grey white irregular mass $(83.34 \%)$ and remaining one case had polypoidal growth $(16.66 \%)$. Majority of them were seen in the fundus $(83.4 \%)$. These results were comparable to the study done by Levy DA et al [17] in which $68 \%$ cases were grey white irregular mass lesions and $60 \%$ of the tumour originate in fundus of the gallbladder. Also comparable to the study done by Kumari $\mathrm{G}$ et al [12] where $90 \%$ of the cases were grey white irregular mass lesions.

Comparison of wall thickness in gallbladder carcinoma of the present study with other studies: According to the present study, statistical analysis revealed significant association of thickness of gallbladder wall grossly and carcinoma gallbladder (at $\mathrm{p}<0.05$ ). $83.4 \%$ of the gallbladder carcinomas were associated with thickened gallbladder wall $(>3 \mathrm{~mm})$ [12]. Hence the association of thickened gallbladder wall with carcinoma gallbladder could be considered. (Table 5).

This result holds good for correlation with the study done by Mittal R et al [18], where $70 \%$ ( 9 cases) of gallbladder carcinomas had thickened wall macroscopically. Also, different studies done by Kumari G et al [12], Haq N et al [19], Romero-Gonzalez RJ et al [20], Levy DA et al [17] had observed increased gallbladder thickness as one of the risk factor for gallbladder carcinoma and advised for thorough gross examination.

Kim et al. conducted the study which explained MDCT findings of hyper enhancing thick inner wall $\geq 2.6 \mathrm{~mm}$ during the portal venous phase, weakly enhancing or nonenhancing thin outer wall $\leq 3.4 \mathrm{~mm}$, and irregular and focal wall thickening indicate a malignant cause of flat gallbladder wall thickening rather than benign disease [21].

A new technique real-time elastography using acoustic radiation force impulse (ARFI) uses high intensity focused ultrasound to evaluate the tissue stiffness in the liver, breast, 
and other organs [22]. It has also been shown to differentiate between benign and malignant nodules in various organs [23]. The likely reason for this difference is that malignant tissues have much higher stiffness due to increased cell density compared to tissues with chronic inflammation and fibrosis [24].

In the study done by Jha $\mathrm{V}$ et al showed out of 20 cases of gallbladder carcinoma, preoperative USG detected an increase in wall thickness in six cases $(30 \%)$ in contrast to gross examination which revealed the same in 55\% (11/20) cases. Therefore, gallbladder carcinoma being a clinical masquerade often evades the eye of a radiologist and comes as pathological surprise. Histopathological examination of cholecystectomy specimens remains the gold standard for the detection of this occult, yet notorious malignancy [25].

Indeed, when gallbladder cancer manifests as wall thickening, it is challenging to diagnose because it mimics the appearance of more common acute and chronic inflammatory conditions of the gallbladder [17]. But the results obtained from the present study emphasised the necessity to gross examine all the cholecystectomy specimens, in order to avoid missing gallbladder carcinoma cases. And histopathological examination is mandated in cases with thickened gallbladder wall.

\section{Conclusion}

Gall bladder diseases have a spectrum of presentation histopathologically. In the present study an attempt was made to demonstrate the association of gross features and carcinoma of gallbladder.

Incidence of gallbladder carcinoma was $1.89 \%$ in the present study. The observations from this study indicated statistical association between increased thickness of gallbladder wall and carcinoma of gallbladder.

\section{What this study adds to existing knowledge?}

The present study emphasised the need of thorough gross examination of all the cholecystectomy specimens and sampling of thickened portion as well as any suspicious area in the gallbladder specimen should be done, in order to avoid missing gallbladder carcinoma cases.

\section{Author's contributions}

Dr. Sujata S Giriyan: Concepts, manuscript review and guided the research work.

Dr. Navyashree N: Literature search, data acquisition, statistics and manuscript preparation.

Funding: No funding sources

Conflict of interest: None declared
Ethical Approval: This study was approved by the Institutional Ethics Committee

\section{References}

1. Nordenstedt H, Mattsson F, El-Serag H, Lagergren JJ. Gallstones and cholecystectomy in relation to risk of intra and extra-hepatic cholangiocarcinoma. Br J Cancer. 2012; 106 (5):1011-1015. doi: 10.1038/bjc.2011.607.

2. Goyal S, Singla S, Duhan A. Correlation between gallstones characteristics and gallbladder mucosal changes: A retrospective study of 313 patients. Clin Cancer Investig J. 2014;3(2):157-161. doi: 10.4103/2278-0513.130215.

3. Stelow EB, Hong SM, Frierson HF. Gallbladder and extrahepatic biliary system. In: Mills S E, editor. Histology for pathologists. 3rd ed. Philadelphia: Lippincott Williams \& Wilkins; 2007.p. 706.

4. Theise ND. Liver and gallbladder. In: Kumar, Abbas, Aster, editors. Robbins \& Cotran Pathologic basis of disease. South Asia ed. Vol 2. Elsevier; 2015. p. 875-880.

5. Horner MJ, Ries LAG, Krapcho M, Neyman N, Aminou R, Howlader N et al. SEER Cancer Statistics Review, 19752006, National Cancer Institute. Bethesda, Md. Available at http://seer. cancer. gov/csr/1975_2006/.

6. Albores-Saavedra J, Henson DE, Klimstra DS. Tumors of the gallbladder, extrahepatic bile ducts, and ampulla of Vater. Atlas of Tumor Pathology. 3rd series. Fascicle 27. Washington DC: Armed Forces Institute of Pathology; 2001. p. 123-141.

7. Albores-Saavedra J, Adsay NV, Crawford JM, Klimstra DS, Kloppel G, Sripa B et al. Carcinoma of gallbladder and extrahepatic bile ducts. Bosman FT, Carneiro F, Hruban $\mathrm{RH}$, Theise ND, editors. WHO Classification of Tumors of the Digestive system. IARC: Lyon 2010. p. 263-78.

8. Rosai J. Gallbladder and extra-hepatic bile ducts. In: Rosai J, editor. Rosai and Ackerman's Surgical Pathology. 10th ed. Edinburgh: Elsevier; 2011. p. 990-97.

9. Gore RM, Yaghmai V, Newmark GM, Belin JW, Miller FH. Imaging of benign and malignant disease of the gallbladder. Radiol Clin N Am. 2002;40(6):1307-1323. doi: https: //doi.org/10.1016/S0033-8389(02)00042-8.

10. Murmu S, Topno VJ, Baitha B. Histopathological study of gallbladder lesions in East Singhbhum, Jharkhand. IOSR J Dent Med Sci. 2017;16(2):1-3. doi: 10.9790/0853-1602 060103.

11. Kumar H, Dundy G, Kini H, Tiwari A, Bhardwaj M. Spectrum of gallbladder diseases- A comparative study in North Vs South Indian population. Ind J Pathol Oncol. 2018; 5(2):273-276. doi: 10.18231/2394-6792.2018.0050. 
12. Kumari G, Deshpande KA, Roy S. Clinicopathological Study of Gallbladder Lesions: Two Years Study. Ann Pathol Lab Med. 2018;5(5):A-456-A-462.

13. Beena D, Shetty J, Jose V. Histopathological spectrum of diseases in gallbladder. Nat J Lab Med. 2017;6(4):6-9. doi: 10.7860/NJLM/2017/23327:2245.

14. Mondal B, Maulik D, Biswas BK, Sarkar GN, Ghosh D. Histopathological spectrum of gallstone disease from cholecystectomy specimen in rural areas of West Bengal, India- an approach of association between gallstone disease and gallbladder carcinoma. Int J Community Med Public Health 2016; 3(11):3229-35. doi: 10.18203/2394-6040. ijcmph 20163941.

15. Sharma I, Choudhury D. Histopathological patterns of gall bladder diseases with special reference to incidental cases-a hospital-based study. Int J Res Med Sci. 2015;3: 3553-3557. doi: http://dx.doi.org/10.18203/2320-6012. Ijrms 20151397.

16. Mohan H, Punia RPS, Dhawan SB, Ahal S, Sekhon MS. Morphological spectrum of gallstone disease in 1100 cholecystectomies in North India. Indian J Surg. 2005; 67 (3):140-142.

17. Levy DA, Murakata LA, Rohrmann CA. Gallbladder Carcinoma: Radiologic-Pathologic Correlation. Radiographics. 2001;21(2):295-314. doi: https://doi.org/10. 1148 / radiographics.21.2.g01 $\mathrm{mr} 16295$.

18. Mittal R, Jesudason MR, Nayak S. Selective histopathology in cholecystectomy for gallstone disease. Indian J Gastroenterol. 2010;29(1):32-36. doi: https://doi. org/ 10.1007/s12664-010-0005-4.

19. Haq N, Khan BA, Imran M, Akram A, Jamal AB, Bangash F. Frequency of gallbladder carcinoma in patients with acute and chronic cholecystitis. J Ayub Med Coll Abbottabad. 2014;26(2);191-193.

20. Romero-Gonzalez RJ, Garza-Flores A, Martinez-Perez Maldonado L, Diaz-Elizondo JA, Muniz-Eguia JJ, Barbosa- Quintana A. Gallbladder selection for histopathological analysis based on a simple method: a prospective comparative study. Ann R Coll Surg Engl. 2012; 94 (3):159-164.doi:10.1308/003588412X1317 1221589810

21. Kim SJ, Lee JM, Lee YJ, Kim SH, Han JK, Choi BI. Analysis of enhancement pattern of flat gallbladder wall thickening on MDCT to differentiate gallbladder cancer from cholecystitis. Am J Roentgenol. 2008; 191(3): 765771. doi: 10.2214/AJR.07.3331.

22. B.J. Fahey, R.C. Nelson, D.P. Bradway, S.J. Hsu, D.M. Dumont, G.E. Trahey. In vivo visualization of abdominal malignancies with acoustic radiation force elastography. Phy Med Biol. 2008;53(1):279-293. doi: 10.1088/00319155/53/1/020.

23. Cho SH, Lee YJ, Han JK, Choi BI. Acoustic radiation force impulse elastography for the evaluation of focal solid hepatic lesions: preliminary findings. Ultras Med Biol. 2010; 36(2): 202-208. doi: 10.1016/j.ultrasmedbio. 2009. 10.009

24. Abhishek V, Avinash V, Patil V, Mallikarjuna MN, Shivaswamy BS. Early diagnosis of gallbladder carcinoma: algorithm approach. Radiol. 2013. doi: http://dx.doi.org/10. 5402/ 2013/239424.

25. Jha V, Sharma P, Mandal KA. Incidental gallbladder carcinoma: Utility of histopathological evaluation of routine cholecystectomy specimens. South Asian J Cancer. 2018;7 (1):21-23. doi: 10.4103/2278-330X.226802.

\section{How to cite this article?}

Navyashree N, Giriyan S.S. Can gallbladder wall thickness by gross examination predicts its carcinoma before histopathological study?. Trop J Path Micro 2019;5(12):1039-1045.doi:10.17511/ jopm.2019.112.12 